\title{
Can health and social care integration make long-term progress? Findings from key informant surveys of the integration Pioneers in England
}

Health and social care integration

Received 21 May 2019 Accepted 13 August 2019

\author{
Bob Erens \\ Faculty of Public Health and Policy, \\ London School of Hygiene and Tropical Medicine, London, UK \\ Gerald Wistow \\ Department of Social Policy, PSSRU, \\ London School of Economics and Political Science, London, UK, and \\ Nicholas Mays, Tommaso Manacorda, Nick Douglas, \\ Sandra Mounier-Jack and Mary Alison Durand \\ London School of Hygiene and Tropical Medicine, \\ London, UK
}

\begin{abstract}
Purpose - All areas in England are expected by National Health Service (NHS) England to develop integrated care systems (ICSs) by April 2021. ICSs bring together primary, secondary and community health services, and involve local authorities and the voluntary sector. ICSs build on previous pilots, including the Integrated Care Pioneers in 25 areas from November 2013 to March 2018. This analysis tracks the Pioneers' self-reported progress, and the facilitators and barriers to improve service coordination over three years, longer than previous evaluations in England. The paper aims to discuss these issues.

Design/methodology/approach - Annual online key informant (KI) surveys, 2016-2018, are used for this study.

Findings - By the fourth year of the programme (2017), KIs had shifted from reporting plans to implementation of a wide range of initiatives. In 2018, informants reported fewer "significant" barriers to change than previously. While some progress in achieving local integration objectives was evident, it was also clear that progress can take considerable time. In parallel, there appears to have been a move away from aspects of personalised care associated with user control, perhaps in part because the emphasis of national objectives has shifted towards establishing large-scale ICSs with a particular focus on organisational fragmentation within the NHS.

Research limitations/implications - Because these are self-reports of changes, they cannot be objectively verified. Later stages of the evaluation will look at changes in outcomes and user experiences. Originality/value - The current study shows clearly that the benefits of integrating health and social care are unlikely to be apparent for several years, and expectations of policy makers to see rapid improvements in care and outcomes are likely to be unrealistic.

Keywords Integrated health and social care, Partnership working, Integrated care

Paper type Research paper

(C) Bob Erens, Gerald Wistow, Nicholas Mays, Tommaso Manacorda, Nick Douglas, Sandra Mounier-Jack and Mary Alison Durand. Published by Emerald Publishing Limited. This article is published under the Creative Commons Attribution (CC BY 4.0) licence. Anyone may reproduce, distribute, translate and create derivative works of this article (for both commercial \& non-commercial purposes), subject to full attribution to the original publication and authors. The full terms of this licence may be seen at: http:// creativecommons.org/licences/by/4.0/legalcode
\end{abstract}




\section{Introduction}

The Integrated Care and Support Pioneer programme was initiated by the Government in England to run over a five-year period (2013-2018), and aimed to improve the quality, effectiveness and cost-effectiveness of care for people whose needs are best met when the different parts of the health and social care systems work in an integrated way. In total, 14 Wave 1 Pioneers were announced in November 2013 (Department of Health, 2013a), joined by a further 11 Wave 2 Pioneers in January 2015 (Department of Health, 2015). Pioneers varied significantly in size, ranging from a "simple" coterminous configuration of one National Health Service (NHS) Clinical Commissioning Group (CCG) and one Local Authority (LA) to much more complex arrangements of multiple CCGs and multiple LAs. The Pioneers were given limited additional funding (initially $£ 20,000$ each, later supplemented with a further $£ 90,000$ ), but were offered support from international experts and a project team at NHS England. Each Pioneer was expected to: drive change at "scale and pace"; encompass whole system integration involving health, social care, public health and potentially other public services, and the voluntary sector; adopt a patient-centred perspective based on the "I Statements" developed by National Voices and Think Local Act Personal (2013); and deliver improved patient experiences, better patient outcomes and financial efficiencies (Department of Health, 2013b).

The then Department of Health (DH) commissioned the Policy Innovation and Evaluation Research Unit (PIRU) to conduct an 18-month "early" evaluation of the Wave 1 Pioneers (Erens et al., 2017). It found considerable heterogeneity in Pioneers' initial aims, but growing convergence over time in the reported activities of most Pioneers towards specific interventions for older people with multiple long-term conditions, with a particular focus on establishing multi-disciplinary teams based in primary care. Moving from design to delivery proved difficult for several reasons, including barriers outside the control of local actors and the increasingly adverse financial setting in which the Pioneers were operating. The early evaluation demonstrated that improving health and social care coordination is not a short-term process.

Following this initial evaluation, DH commissioned a five-year evaluation starting in July 2015 to assess the extent to which the 25 Pioneers were successful in providing better coordinated care, including improved patient experience and outcomes, in a cost-effective way. This longer-term evaluation consists of several work packages, one of which includes annual online surveys of key informants (KIs) (mainly managers) from the 25 Pioneers in order to capture their perceptions of factors helping or hindering their development of integrated care, and their progress over time. This paper provides results from the three KI surveys carried out in 2016-2018, focusing on changes over time in four key areas: the most important integration objectives locally; progress towards meeting those objectives; barriers to progressing integration; and facilitators of integration. The duration of this evaluation provides a rare opportunity to study the longer-term evolution of attempts in a range of sites across England to improve the coordination of health care provided by the NHS and the separate long-term care sector funded by local government. Most evaluations extend between one and two years only (e.g. Forder et al., 2018; Windle et al., 2009; RAND Europe, Ernst \& Young, 2012), and participants in the Pioneers, as well as in similar programmes, generally argue that significant system change requires three to five years to secure (e.g. Erens et al., 2016; RAND Europe, Ernst \& Young, 2012).

The evaluation was approved by the LSHTM Observation Research Ethics Committee (reference 7215) in March 2014.

\section{Methods}

The three KI surveys followed the same methodology. The aim was to include a spread of KIs within each Pioneer, with at least one person from each participating CCG and LA, as well as one person from any other important local participating partners (e.g. acute hospitals, community health services, voluntary sector organisations and patient representatives). 
The research team had the name of one lead contact for each Pioneer. The leads were typically middle or senior managers, and were most often based in a CCG or LA. The lead contact in each Pioneer was asked to provide the names and e-mail addresses of key individuals before the 2016 survey. Leads were also asked to provide the names and e-mail addresses of every member of the Pioneer "board". If no such body existed, we asked for contact details of the group responsible for steering local health and social care integration.

The number of KIs on the mailing list varied by Pioneer, partly due to the size of the Pioneer board, and partly a reflection of the variation in the size of the Pioneer.

The leads were asked to update the lists before each of the subsequent surveys and the majority did. In sites where lists were not updated, the original list was used. For the latter two surveys, KIs were asked whether any other senior staff in their area should be sent the questionnaire, and any new names provided were e-mailed a survey invitation.

The KI survey involved an online questionnaire, which was programmed using Qualtrics software. All three surveys included questions on barriers and facilitators to integration and progress to date. The majority of questions were pre-coded.

Data collection methods were identical for the three surveys, with an initial e-mail invitation followed by several reminder e-mails. Table I shows the data collection periods, mailing list sizes and participant numbers for the surveys. The surveys covered the period from the start of the Pioneers to autumn 2018, which give an interval of at least four years.

Although the individual response rate fell over the three surveys, the value of the response rate for a KI survey is questionable, since such surveys are not asking individuals to report on their own behaviour or role within their organisations, but to provide data about their organisation based on their specialised knowledge. It is not necessary for KI surveys to obtain a "representative sample". Instead the aim is to purposively select individuals who are able to shed light on the key topics included in the study (Hughes and Preski, 1997; Von Korff et al., 1992). Each survey achieved a spread of informants from different types of organisation.

\section{Results}

Key informant characteristics

In 2016, at least one KI participant completed the survey in all 25 Pioneers; in 2017, there was at least one KI from 24 Pioneers; and in 2018, there were KI participants from 23 Pioneers. In total, $15 \mathrm{KIs}$ participated in all three surveys, and a further 38 participated in two of the three.

Most KIs were from three types of organisations (Table II): CCGs, LAs and NHS providers (mostly not only acute trusts, but also general practice, community or mental health trusts). The "Other" category was a mixture of KIs working for voluntary organisations, private providers (e.g. care homes) or patient representative organisations (e.g. Healthwatch, the local NHS consumer organisation). There were around 20-25 KIs in each organisation type in each survey.

Aside from a few GPs, our KIs tended to be managers who did not have day-to-day contact with patients/service users. In each survey, most Pioneer leads participated.

\section{Integration initiatives in 2018}

Table III shows responses to a 2018 survey question asking which "services, infrastructure or workforce developments have been implemented” locally. KIs were shown ten initiatives,

\begin{tabular}{|c|c|c|c|c|c|}
\hline Survey year & Data collection period & $\begin{array}{c}\text { Mailing list } \\
n\end{array}$ & $\begin{array}{c}\text { Participants } \\
n \\
\end{array}$ & $\begin{array}{c}\text { Response rate } \\
\% \\
\end{array}$ & \\
\hline 2016 & April-June 2016 & 337 & 98 & 29 & $\begin{array}{c}\text { Table I. } \\
\text { Data collection periods }\end{array}$ \\
\hline 2017 & June-September 2017 & 482 & 105 & 22 & and sample sizes for \\
\hline 2018 & September-November 2018 & 439 & 85 & 19 & the three KI surveys \\
\hline
\end{tabular}

Health and social care integration

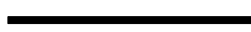




\begin{tabular}{ccc}
$n$ & $n$ & $n$ \\
\hline 98 & 105 & 85 \\
& & \\
61 & 62 & 54 \\
37 & 43 & 31
\end{tabular}

Pioneer wave

Wave 1

Wave 2

Organisation worked for

$\begin{array}{llll}\text { Clinical Commissioning Group (CCG) } & 26 & 22 & 27\end{array}$

Local Authority (LA)

NHS provider (e.g. primary care, acute trust)

$\begin{array}{lll}26 & 22 & 27 \\ 24 & 33 & 22 \\ 23 & 22 & 24 \\ 25 & 28 & 12\end{array}$

Job title/role

Table II.

Key informant characteristics by survey year
Pioneer/other local integration lead

Chief executive $^{\mathrm{a}}$

Director/assistant director

Locality manager
Other senior manager

Health care professional (clinical)

Other (including lay representatives)

$\begin{array}{rr}19 & 16 \\ 19 & 6 \\ 30 & 24 \\ 4 & 5 \\ 21 & 21 \\ 7 & 10 \\ 5 & 3\end{array}$

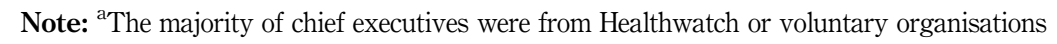

Table III.

Services/initiatives implemented locally by Pioneer (2018)

\begin{tabular}{|c|c|c|c|c|c|c|c|c|c|c|}
\hline \multirow[b]{2}{*}{ Pioneer $^{\mathrm{a}}$} & \multicolumn{10}{|c|}{ Services/initiatives implemented locally ${ }^{\mathrm{b}}$} \\
\hline & 1 & 2 & 3 & 4 & 5 & 6 & 7 & 8 & 9 & 10 \\
\hline Airedale, Wharfedale and Craven & $x$ & $x$ & $x$ & & & & $x$ & $x$ & $x$ & \\
\hline Barnsley & $x$ & $x$ & $\mathrm{x}$ & & & $x$ & $x$ & $x$ & $x$ & \\
\hline Camden & $x$ & $x$ & $\mathrm{x}$ & & $x$ & $x$ & $x$ & $X$ & $x$ & \\
\hline Cheshire & $x$ & $x$ & $\mathrm{x}$ & $\mathrm{x}$ & $x$ & $x$ & $x$ & $x$ & $x$ & $x$ \\
\hline East London (WEL) & $x$ & $x$ & $\mathrm{x}$ & $\mathrm{x}$ & $x$ & $x$ & $x$ & $x$ & $x$ & $x$ \\
\hline Greater Manchester & $x$ & $x$ & $\mathrm{x}$ & $\mathrm{x}$ & $x$ & $x$ & $x$ & $x$ & $x$ & \\
\hline Greenwich & $x$ & $x$ & $x$ & & $x$ & $x$ & & $x$ & $x$ & \\
\hline Islington & $x$ & $x$ & $\mathrm{x}$ & & $x$ & $x$ & $x$ & & $\mathrm{x}$ & \\
\hline Kent & $x$ & $x$ & $\mathrm{x}$ & $\mathrm{x}$ & $x$ & $x$ & $x$ & $x$ & $x$ & $x$ \\
\hline Leeds & $x$ & $x$ & $\mathrm{x}$ & $x$ & $x$ & $x$ & $x$ & $x$ & $x$ & $x$ \\
\hline Nottingham City & $x$ & $x$ & $x$ & & & & $x$ & $X$ & $\mathrm{x}$ & \\
\hline Nottingham County & $x$ & $x$ & $x$ & $x$ & $x$ & $x$ & $x$ & $\mathrm{X}$ & $\mathrm{x}$ & $x$ \\
\hline North West London & $x$ & $x$ & $x$ & $\mathrm{x}$ & $\mathrm{x}$ & $x$ & $x$ & $\mathrm{X}$ & $\mathrm{x}$ & \\
\hline Sheffield & $x$ & $x$ & $x$ & & & & $x$ & & $x$ & \\
\hline South Devon and Torbay & $x$ & $x$ & $x$ & & $\mathrm{x}$ & $x$ & $x$ & $\mathrm{x}$ & $\mathrm{x}$ & \\
\hline South Somerset & $x$ & $x$ & $x$ & & & & & & $x$ & $x$ \\
\hline South Tyneside & $x$ & $x$ & $x$ & $\mathrm{x}$ & $x$ & $x$ & $x$ & $x$ & $x$ & $x$ \\
\hline Southend & $x$ & $x$ & $\mathrm{x}$ & $\mathrm{x}$ & $\mathrm{x}$ & $x$ & $x$ & $x$ & $x$ & \\
\hline Staffordshire and Stoke & $x$ & & $\mathrm{x}$ & & & & & $x$ & $x$ & \\
\hline Vale of York & $x$ & $x$ & $x$ & $x$ & & & $x$ & & $x$ & \\
\hline Wakefield & $x$ & $x$ & $\mathrm{x}$ & & $\mathrm{x}$ & $x$ & $x$ & $x$ & $x$ & \\
\hline West Norfolk & $x$ & $x$ & $x$ & & & $x$ & & & $x$ & \\
\hline Worcestershire & $x$ & $x$ & $\mathrm{x}$ & $\mathrm{x}$ & $\mathrm{x}$ & $x$ & $x$ & $x$ & $x$ & $x$ \\
\hline
\end{tabular}

Notes: ${ }^{\mathrm{a}}$ Two Pioneers (Blackpool and Fylde Coast and Cornwall) are not included in the table, as no KIs from those sites completed the 2018 survey. ${ }^{\text {KKey }}$ to the ten initiatives asked about: $1=$ community-based multi-disciplinary teams (MDTs) including both health and social care; $2=$ social prescribing initiatives; $3=$ care navigators/care coordinators; $4=$ generic care workers; $5=$ shared IT systems; $6=$ shared patient records; $7=$ shared/integrated health and social care budgets; $8=$ community hubs; $9=$ use of the voluntary sector to help provide local integrated services; $10=$ an adaptation of an international integration model to the English context (e.g. the Buurtzorg model) 
compiled from the earlier KI surveys as well as qualitative interviews in each Pioneer, and asked to tick all that were implemented locally. An "X" in Table III indicates that at least one $\mathrm{KI}$ in that Pioneer said the particular initiative was implemented. If there is no " $\mathrm{X}$ " under a particular initiative, it does not mean it had not been implemented in that area; it may simply be that the KIs were not aware of the initiative. Also, the initiatives may not have been interpreted by all KIs in the same way, and some of these categories could potentially refer to quite different types of initiatives in different Pioneers.

It is notable that there are relatively few empty cells in Table III. With 10 columns of initiatives and 23 rows of Pioneers, there are 230 cells in total; of these, 179 cells have an "X", which is 78 per cent. The overall impression, therefore, is that there was a great deal of activity in terms of initiatives designed to support the integration of local health and social care services.

Also notable is that some of the initiatives are common across all (or nearly all) Pioneers, including community-based MDTs, social prescribing, care navigators and use of the voluntary sector. In addition, shared patient records, shared health and social care budgets and community hubs were reported as implemented in at least three in four areas.

A third feature is that, while many areas were implementing a range of integrated services, these were typically inter-connected (e.g. community-based MDTs often make use of care navigators and may rely on shared patient records). In total, 7 of the 23 Pioneers ticked all ten initiatives, while a further six Pioneers ticked eight of the ten.

\section{Most important objectives of local integration}

In 2017 and 2018, KIs were shown a list of eight objectives/outcomes that integration activities often aim to achieve, and were asked to select the three "most important objectives/outcomes that had shaped the health and social care integration activities" in their area.

In the space of one year, there were some notable shifts in the objectives which KIs identified as being the "most important"; these are more pronounced when looking at organisation type (Table IV). KIs from CCGs showed the biggest shifts, with less importance for: "reducing unplanned hospital admissions" (48 per cent, down from 64 per cent in 2017); and

\begin{tabular}{|c|c|c|c|c|c|c|}
\hline "Most important" objectives/outcomes & & $\begin{array}{c}\mathrm{CCG} \\
\%\end{array}$ & $\begin{array}{c}\text { Local } \\
\text { authority } \\
\%\end{array}$ & $\begin{array}{l}\text { NHS } \\
\text { provider } \\
\%\end{array}$ & $\begin{array}{c}\text { Other } \\
\%\end{array}$ & $\begin{array}{c}\text { All } \\
\% \\
\end{array}$ \\
\hline \multirow[t]{2}{*}{ Patients/service users experiencing more joined up services } & 2017 & 55 & 58 & 73 & 75 & 65 \\
\hline & 2018 & 70 & 82 & 75 & 83 & 76 \\
\hline \multirow{4}{*}{$\begin{array}{l}\text { Patients/service users being better able to manage their } \\
\text { own care and health } \\
\text { Reducing unplanned hospital admissions }\end{array}$} & 2017 & 59 & 64 & 41 & 50 & 54 \\
\hline & 2018 & 44 & 50 & 33 & 42 & 46 \\
\hline & 2017 & 64 & 39 & 73 & 43 & 52 \\
\hline & 2018 & 48 & 36 & 75 & 33 & 51 \\
\hline \multirow[t]{2}{*}{ Improving quality of care for patients/service users } & 2017 & 27 & 39 & 41 & 46 & 39 \\
\hline & 2018 & 44 & 36 & 63 & 50 & 48 \\
\hline \multirow{2}{*}{$\begin{array}{l}\text { Reducing, on average, per patient health and social } \\
\text { care costs }\end{array}$} & 2017 & 50 & 39 & 23 & 29 & 35 \\
\hline & 2018 & 41 & 32 & 17 & 0 & 26 \\
\hline \multirow[t]{2}{*}{ Improving quality of life for patients/service users } & 2017 & 18 & 36 & 23 & 11 & 23 \\
\hline & 2018 & 37 & 41 & 21 & 42 & 34 \\
\hline \multirow{4}{*}{$\begin{array}{l}\text { Patients/service users having a greater say in the } \\
\text { care they receive } \\
\text { Services becoming more accessible to } \\
\text { patients/service users }\end{array}$} & 2017 & 9 & 9 & 9 & 14 & 11 \\
\hline & 2018 & 0 & 14 & 4 & 17 & 7 \\
\hline & 2017 & 9 & 6 & 14 & 11 & 10 \\
\hline & 2018 & 15 & 9 & 13 & 33 & 15 \\
\hline
\end{tabular}

Notes: Columns add to more than 100 per cent, as informants were asked to select the three most important objectives/outcomes. 2017 bases: $\mathrm{CCG}=22$; $\mathrm{LA}=33$; NHS provider $=22$; other $=28$; all $=105$. 2018 bases: $\mathrm{CCG}=27$; $\mathrm{LA}=22$; NHS provider $=24$; other $=12$; all $=85$

Health and social care integration

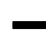

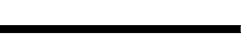


"patients/service users better able to manage their own care" (44 per cent, down from 59 per cent). Of greater importance were: "patients/service users experiencing more joined up services" (70 per cent, up from 55 per cent); "improving quality of care" (44 per cent, up from 27 per cent); and "improving quality of life" (37 per cent, up from 18 per cent).

KIs from LAs were also more likely to say that "patients/service users experiencing more joined up services" was important ( 82 per cent, up from 58 per cent), but were less likely to identify "patients/service users better able to manage their own care" as important (50 per cent, down from 64 per cent). NHS providers gave similar results in both years, aside from an increase in those identifying "improving quality of care" as important (63 per cent, up from 41 per cent in 2017).

Progress towards meeting integration objectives

KIs were asked how much progress there had been in meeting the eight objectives as a result of local health and social care integration initiatives.

Responses are consistent across survey year, with relatively few reports of "substantial" or "no progress" for most of the objectives (Table V). Given the broad middle category

\begin{tabular}{llll}
\hline Objectives/outcomes & Substantial & Some & Progress \\
\hline
\end{tabular}

Patients/service users are now able to experience services that are more joined up

$\begin{array}{lcccrr}2016 & \% & 9 & 72 & 8 & 11 \\ 2017 & \% & 15 & 73 & 7 & 5 \\ 2018 & \% & 21 & 66 & 11 & 1\end{array}$

The quality of care for patients/service users has improved

$\begin{array}{llllll}2016 & \% & 12 & 61 & 8 & 9 \\ 2017 & \% & 13 & 75 & 8 & 5 \\ 2018 & \% & 9 & 80 & 8 & 4\end{array}$

Services are now more accessible to patients/service users

$\begin{array}{lcccrr}2016 & \% & 9 & 73 & 9 & 9 \\ 2017 & \% & 9 & 63 & 16 & 13 \\ 2018 & \% & 9 & 70 & 15 & 6\end{array}$

The quality of life for patients/service users has improved

$\begin{array}{llllrl}2016 & \% & 8 & 62 & 9 & 21 \\ 2017 & \% & 5 & 73 & 12 & 11 \\ 2018 & \% & 5 & 74 & 11 & 10\end{array}$

Patients/service users now have a greater say in the care they receive

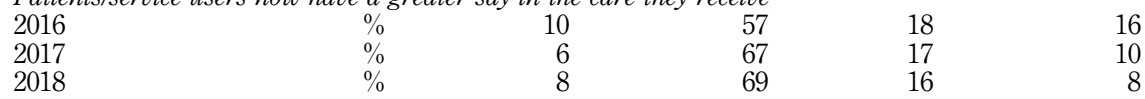

Patients/service users are now better able to manage their own care and health

\begin{tabular}{|c|c|c|c|c|}
\hline 2016 & $\%$ & 9 & 61 & 11 \\
\hline 2017 & $\%$ & 5 & 69 & 14 \\
\hline 2018 & $\%$ & 4 & 79 & 10 \\
\hline
\end{tabular}

Unplanned admissions have reduced

$\begin{array}{lcrrrr}2016 & \% & 12 & 34 & 37 & 17 \\ 2017 & \% & 7 & 60 & 23 & 11 \\ 2018 & \% & 10 & 70 & 19 & 1\end{array}$

\section{Table V.}

Progress of the Pioneer programme in meeting key objectives/outcomes, by survey year

On average, per patient/service user health and social care costs have decreased

2016

2017

2018

$\begin{array}{ll}\% & 4 \\ \% & 3 \\ \% & 5\end{array}$

11

40

30

29

54

27

19

Notes: Bases: $2016=90 ; 2017=104 ; 2018=80$ 
("some progress"), it is perhaps not surprising that most KIs selected this category every year. Even so, the responses indicate, first, that KIs reported at least "some progress" in nearly all of these objectives in all survey years and, second, that progress was more likely to be reported in 2018 than in 2016 for all but one of the objectives (the exception being "more accessible services"), and equally or more likely to be reported in 2018 than in 2017 for all objectives (Figure 1).

\section{Barriers to integrating health and social care services}

The KIs were shown a list of "potential barriers to health and social care services working together effectively" and asked whether each one had been a "very", "fairly" or "not a significant barrier" over the past 12 months. We now have three years of data to examine the extent to which barriers are reported to have changed or been mitigated over time.

The list of barriers was compiled from those found in other research projects, as well as from our interviews with managers involved in setting up the Pioneers (Erens et al., 2016; Cameron et al., 2012; Goodwin et al., 2013; Wilkes, 2014). The list varied slightly between the surveys, but 12 items were repeated in all years. The percentages in 2018 reporting "very significant" barriers were lower than in 2017 for all items but one, and sometimes were substantially lower (Figure 2). The biggest reductions between 2017 and 2018 were for "information governance regulations making it difficult to share patient information" (2018: 16 per cent; 2017: 34 per cent) and "incompatible IT systems make it difficult to share patient/service user information” (2018: 30 per cent; 2017: 47 per cent). Despite the

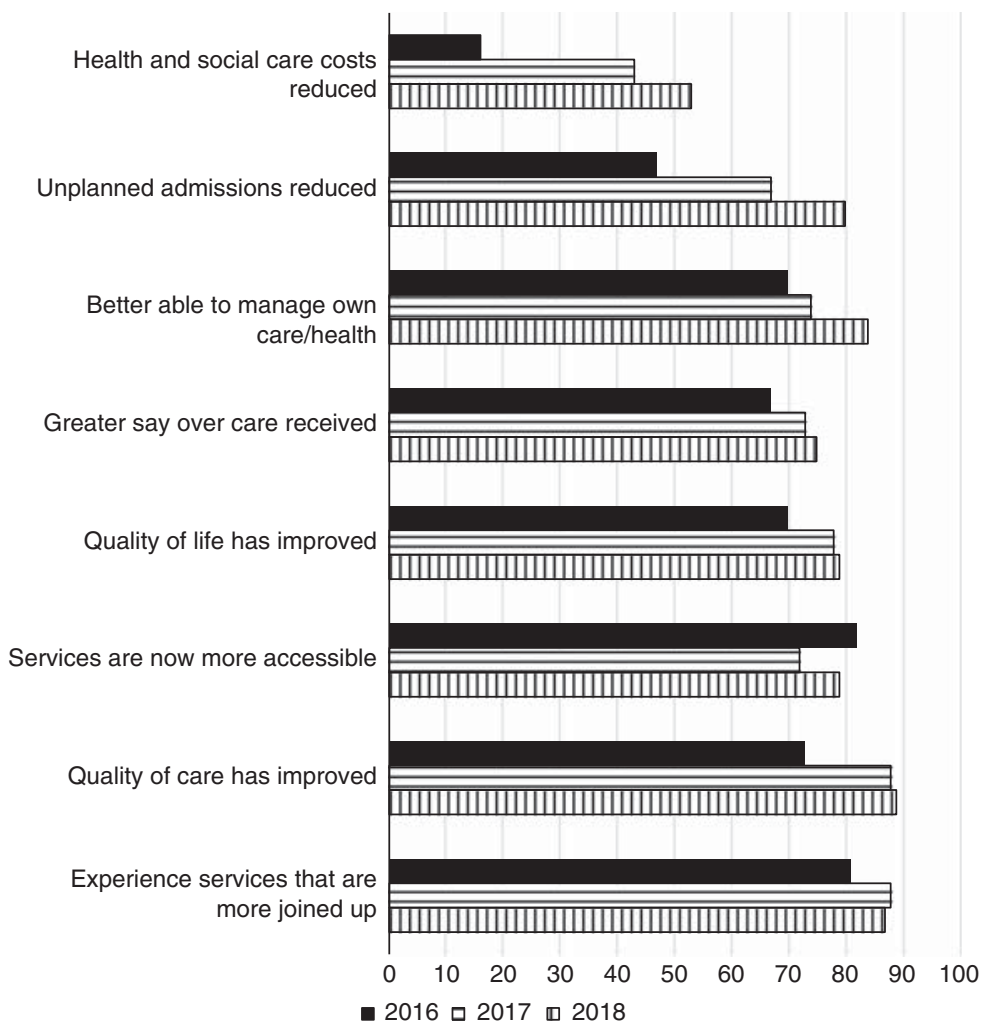

Notes: Bases: $2016=90 ; 2017=104 ; 2018=80$
Health and social care integration

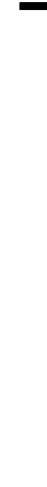


JICA

Figure 2.

"Very significant" barriers to integration by survey year $(\%)$

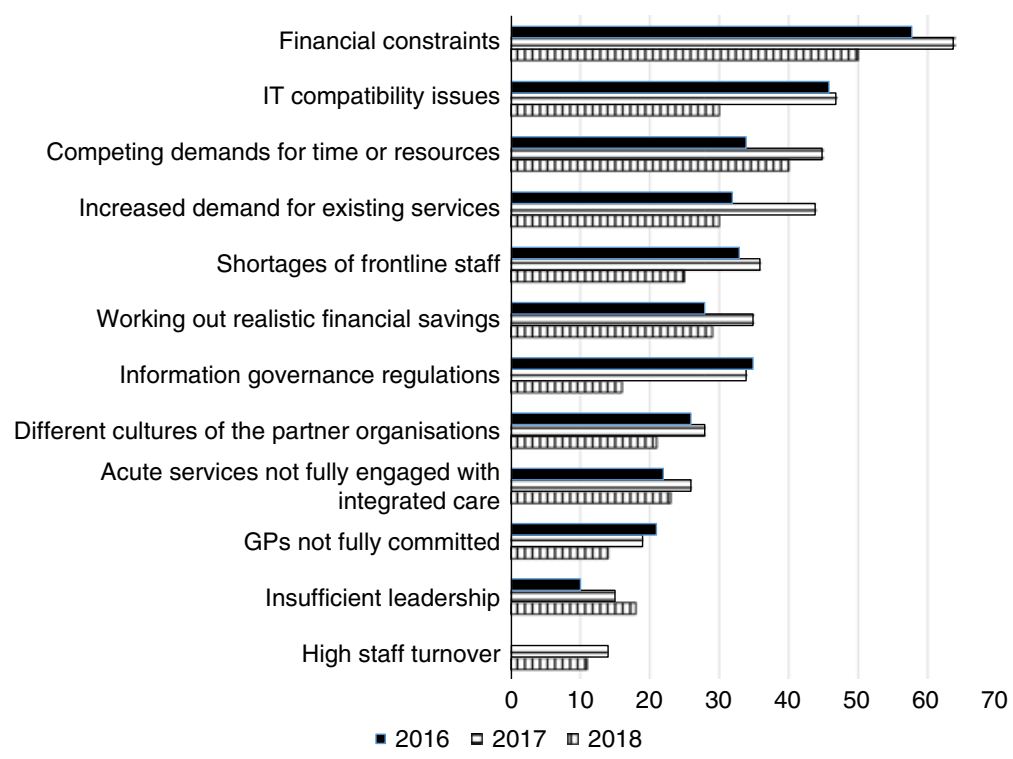

Notes: Bases: $2016=97 ; 2017=98 ; 2018=80$. "High staff turnover" was not asked in 2016

continuation of real terms cuts in funding for most public services in 2018, it is noteworthy that the barrier of "Significant financial constraints within the local health and social care economy" decreased from 64 to 50 per cent between 2017 and 2018, while the related barrier "Increased demand for existing services" decreased from 44 to 30 per cent. Comparing 2018 responses with those from 2016, the picture is more mixed, as seven barriers are lower in 2018, but four are higher or the same. In 2018, only two barriers ("financial constraints" and "competing demands for time or resources") were mentioned by one-third or more of KIs as "very significant", compared to seven barriers in 2017 and six in 2016.

\section{Facilitators of integrating health and social care services}

KIs were shown a list of potential facilitators and asked how important these "enablers/ facilitators [have] been in supporting local health and social care integration activities" over the past 12 months. The response categories were "very", "fairly", "not very" and "not at all important”.

Six of the nine facilitators were less likely to be mentioned as "very important" in 2018 than in 2017, two were largely the same and one (local voluntary organisations actively involved) showed a small increase (Figure 3). Two of the largest reductions over the three-year period were found for facilitators associated with a patient-centred approach, which was a defining feature of the Pioneer programme at its start. It appears that this may now be less central to integration activities: "I statements to adopt a patient perspective" decreased from 49 per cent in 2016 to 27 per cent in 2017 and then to 15 per cent in 2018; and "involving patients/service users/carers in co-design" decreased from 55 to 39 per cent and then to 34 per cent over this period.

\section{Discussion}

The results presented above are from surveys of KIs in 25 Pioneer sites, one of several elements of PIRU's five-year evaluation of the Pioneers. Three surveys have been conducted 


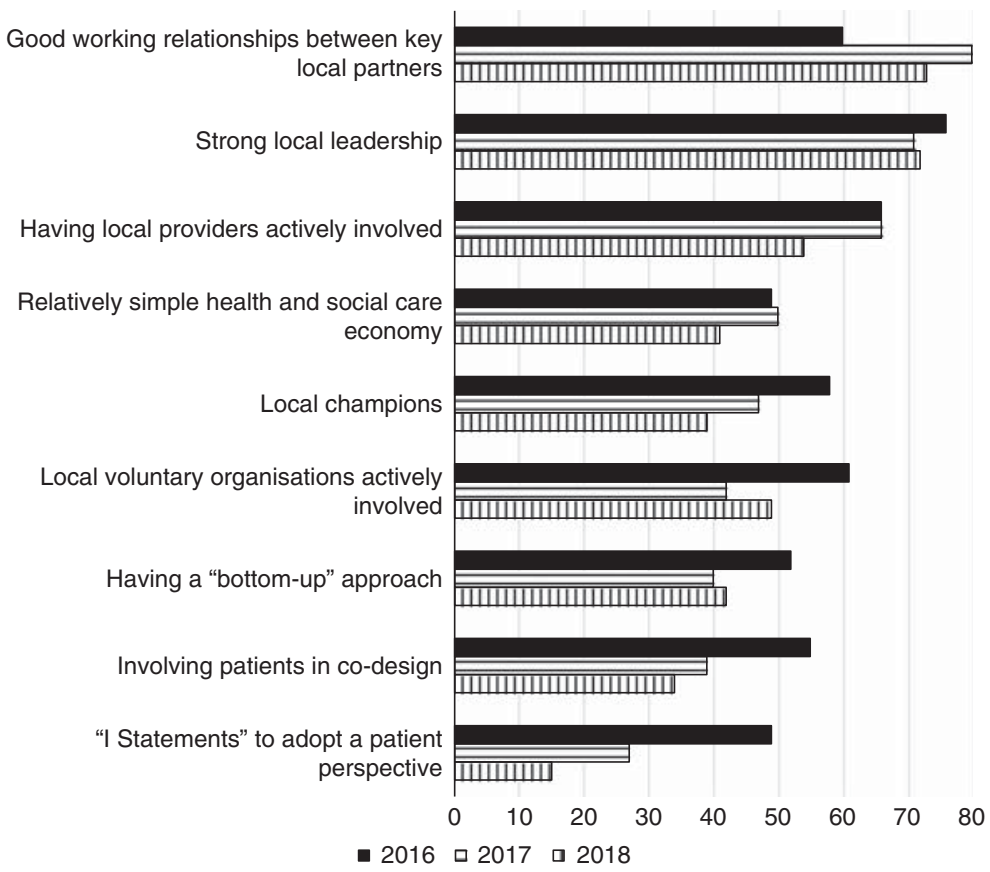

Health and social care integration

Notes: Bases: $2016=96 ; 2017=96 ; 2018=80$

(2016, 2017, 2018), providing snapshots of developments in 25 areas of England selected by central government as exemplars of integrated working.

Our approach has several limitations. First, it relies on self-reported and unverifiable data. Second, the KIs may be closely involved in designing and implementing Pioneer programmes. Thus, their perceptions risk being influenced by confirmation and optimism bias as well differences in access to knowledge associated with KI's different organisational roles (Hughes and Preski, 1997). Other factors potentially influence the accuracy of KI perceptions, including errors of recall, their interpersonal networks and levels of experience or expertise (Mezias and Starbuck, 2003). Third, the KI respondents have changed over the three surveys, reflecting changes of staff involved in local integration activities. Whether differences between surveys are due to changes in KI views or are simply an artefact of different KIs responding to the surveys is uncertain. The risks of bias are partly mitigated by securing responses from KIs representing all Pioneers and a wide range of organisations, but these limitations must be kept in mind.

On the other hand, our approach has a number of advantages over many previous attempts to evaluate integration initiatives, which have often relied on qualitative interviews carried out over shorter time spans and/or routinely collected administrative data which provide only proxy indicators of integrated working (e.g. Delayed Transfers of Care) and very little evidence about individuals' experiences of receiving integrated care (Raleigh et al., 2014). Despite its limitations, our evaluation enables us to conduct annual surveys among a sample of KIs centrally involved in integration in 25 areas, and which includes repeated questions to explore possible changes over time.

Implementing the national vision for coordinated and personalised care

Results from the 2017 KI survey showed that Pioneers had moved from planning local programmes to implementing them (Erens et al., 2018). The extensive range of integration 
initiatives reported in 2018 suggests that Pioneers were continuing to develop a wide range of integrated services (Table II). However, there are also indications of changes in development strategies. In particular, KIs reported quite sizeable changes in the local importance of some key integration objectives (Table IV), together with changes in the extent of progress in implementing key objectives (Figure 1).

The limitations of our evidence should be recalled here. Nonetheless, our findings are especially interesting in terms of the role of Pioneers in realising the "ambitious vision" of integration as a means of making person-centred coordinated care and support the norm across England within five years (National Collaboration for Integrated Care and Support, 2013). Both components of this vision were important local objectives. In 2018, "users experiencing more joined up services" remained (by some considerable distance) the most frequently reported objective, and at 76 per cent was 11 percentage points higher than in 2017. However, there were indications that some elements of the personalisation component of the national vision were becoming less important locally. On the one hand, while "users being better able to manage their own care" was the fourth most frequently reported local objective at 46 per cent, this was lower than the 54 per cent reported in 2017 (and among KIs who completed both surveys, the reduction was much greater, from 59 per cent in 2017 to 33 per cent in 2018). In addition, "users having a greater say in the care they receive" was considered a very important local objective by only 7 per cent in 2018. For "improving the accessibility of services", the equivalent figure for KIs was just 15 per cent.

These findings do not appear to mean that user-centred objectives were generally thought to be unimportant: improving the quality of care and quality of life were considered important local objectives by 48 and 34 per cent of KIs, respectively, and both figures increased by around ten percentage points between 2017 and 2018. However, it is interesting to note that these last two objectives could be seen as components of a relatively weak version of personalisation, one which does not imply a transfer of power and control to users. By contrast, greater say and self-management are both aspects of a stronger version based on such transfers. It is possible that these findings reflect a shift in national objectives from an emphasis on personalised care towards establishing large-scale integrated care systems with a particular focus on organisational fragmentation within the NHS. The impact on our findings of this shift in focus may be reinforced by the relative absence of KI participants involved in direct service delivery.

Our interpretation of these findings would be helped by data about the local baselines at the beginning of the Pioneer programme in November 2013. Such data are not available as the evaluation was commissioned in 2015 . However, we have data on progress in implementation collected in 2016-2018. The data are based on KIs' recording whether progress in achieving eight objectives could be described as "substantial", "some" or "none" (Table V). Positive progress ("substantial" or "some") was reported for each of the eight objectives in 2016 and in only one case (making services more accessible) was the percentage reporting such progress lower in 2018 than in 2016. It is possible that the lower importance attached locally to some objectives reflects the view that sufficient progress is being achieved or that diminishing returns have set in and other objectives have become relatively more important or achievable. We will explore such issues in subsequent qualitative interviews and analyses of routine data about costs and activities where these are available.

A further caveat about the extent of progress reported is that the vast majority of KIs reported "some" progress in meeting objectives, but very few reported "substantial" progress. This finding supports the view expressed by KIs from the beginning of our evaluation (and findings from evaluations of other initiatives) that the benefits of integrating services would not be apparent for several years and it was unrealistic to expect results "at scale and pace" as specified by $\mathrm{DH}$ in 2013. 
Overcoming barriers to integrated care?

Perhaps, the most surprising result in 2018 was the lower percentages of KIs who reported as "very significant" most of the 12 barriers specified (Figure 2). This was unexpected since the significance of the same barriers was reported to have increased markedly in 2017, and many had been cited elsewhere (Cameron et al., 2012; Frontier Economics, 2012; Wilkes, 2014). (While potentially an artefact of the change in KIs between surveys, similar results were found among the sub-group of KIs who participated in more than one survey.) The research team will explore through its other data collections whether there is further evidence of barriers becoming less significant.

There are several possible explanations to examine. One is whether the effects of the barriers have been removed or attenuated due to action from the centre or to local actors developing "workarounds" which mitigate their influence. Indeed, national bodies have advocated such workarounds in the case of, for example, information governance and incompatibilities of IT systems. A second is that the implementation of Pioneer programmes is supporting the development of infrastructures and skills that were previously lacking, including the build-up of experience in designing and commissioning new ways of working and models of care; recruiting more frontline staff; training staff in cross-agency and multidisciplinary working; and adjusting to austerity as part of the context in which they operate rather than a barrier to development. LA interests have argued that they have innovated to mitigate the full effects of the substantial budget cuts they have experienced, though their capacity to do so is becoming stretched to breaking point, as the Northamptonshire case has demonstrated (Knight, 2018). It is also possible that the July 2018 announcement of £20.5bn growth for the NHS over five years had influenced KI attitudes to financial barriers when this survey was conducted. Third, the continuing national attention given to integration could result in local areas feeling that they must now focus on delivering integrated services regardless of the barriers they encounter, and thus are less likely to highlight them.

At the earlier stages of our evaluation, we highlighted an "integration paradox": as the need for effective integration intensifies to improve outcomes and save costs within an increasingly adverse financial setting, so it becomes more difficult to secure change due to the same pressures of increased demand and fewer resources, which often result in a retreat into more "siloed" ways of working. While the pressures of increasing demand and financial austerity have not diminished, and have potentially been amplified by the deteriorating workforce situation within both the NHS and social care, the 2018 survey suggests progress is continuing (even if slowly). At the same time, it is also clear from our experience in the field, and the continuing national initiatives to secure improvements to integrated care (e.g. NHS England and Partners, 2014; NHS England, 2015, 2019), that the extent of progress falls short of the initial objective for the Pioneers of integrated care becoming the norm in five years (National Collaboration for Integrated Care and Support, 2013). The research team will, therefore, continue to monitor the extent to which progress continues over the next 18 months, and whether local areas can overcome the many difficulties they face in providing better coordinated services.

The possibility of being able to look at developments over this longer period is a significant benefit of our five-year evaluation. In addition to the KI surveys, the evaluation is monitoring routinely collected administrative data over successive years for a number of high-level indicators (such as unplanned hospital admissions, emergency admissions and delayed transfers of care) to examine whether local initiatives in Pioneer areas are reflected in different trajectories in these population-level indicators when compared to non-Pioneer areas. We are also conducting in-depth evaluations of specific local initiatives (i.e. primary care led multi-disciplinary teams) in several sites, during which evidence on user and staff experiences will be collected. Thus, the surveys are not only important as a rolling series of snapshots of developments in the Pioneers but also highlight issues to be addressed by other means in our evaluation.
Health and social care integration 


\section{Acknowledgements}

The authors would like to thank the members of staff in all the former Pioneer sites who completed the online surveys between 2016 and 2018. This project is an independent evaluation funded by the National Institute for Health Research (NIHR) Policy Research Programme (project reference PR-R10-1014-25001, "Evaluation of the Integrated Care and Support Pioneer Programme in the Context of New Funding Arrangements for Integrated Care in England"). The views expressed are those of the author(s) and not necessarily those of the NIHR or the Department of Health and Social Care.

\section{References}

Cameron, A., Lart, R., Bostock, L. and Coomber, C. (2012), Factors that Promote and Hinder Joint and Integrated Working between Health and Social Care Services, Research Briefing No. 41, Social Institute for Excellence, London, available at: www.scie.org.uk/publications/briefings/ briefing41/ (accessed 10 May 2019).

Department of Health (2013a), "Integration pioneers leading the way for health and care reform", Press Release, available at: www.gov.uk/government/news/integration-pioneers-leading-the-way-forhealth-and-care-reform-2 (accessed 10 May 2019).

Department of Health (2013b), "Letter inviting expressions of interest for health and social care integration 'pioneers'”, available at: www.gov.uk/government/publications/social-careintegration-pioneers (accessed 10 May 2019).

Department of Health (2015), "Integrated health and social care programme expanded", available at: www.gov.uk/government/news/integrated-health-and-social-care-programme-expanded (accessed 10 May 2019).

Erens, B., Wistow, G., Mounier-Jack, S., Douglas, N., Jones, L., Manacorda, T. and Mays, N. (2016), "Early evaluation of the Integrated Care and Support Pioneers programme: final report", Policy Innovation Research Unit, London, available at: http://piru.lshtm.ac.uk/assets/files/Early_ evaluation_of_IC_Pioneers_Final_Report.pdf (accessed 10 May 2019).

Erens, B., Wistow, G., Mounier-Jack, S., Douglas, N., Manacorda, T., Durand, M.A. and Mays, N. (2017), "Early evaluation of the integrated care and support pioneers programme", Journal of Integrated Care, Vol. 25 No. 3, pp. 137-149, available at: www.emeraldinsight.com/doi/abs/10.1108/JICA12-2016-0047 (accessed 10 May 2019).

Erens, B., Manacorda, T., Douglas, N., Durand, M.A., Hoomans, T., Mounier-Jack, S., Wistow, G. and Mays, N. (2018), Results from the Second Survey (Spring/Summer 2017) of Pioneer Key Informants, Policy Innovation Research Unit, London, available at: http://piru. lshtm.ac.uk/assets/files/IC\%20Pioneers \%202017\%20KI\%20Survey\%20Report.pdf (accessed 10 May 2019).

Forder, J., Caiels, J., Harlock, J., Wistow, G., Malisauskaite, G., Peters, M., Marczak, J., D’Amico, F., Fernandez, J.-L., Fitzpatrick, R. and Jones, K. (2018), "A System-level Evaluation of the Better Care Fund: final report”, Quality and Outcomes of Person-Centred Care Policy Research Unit, Canterbury, available at: www.pssru.ac.uk/pub/5424.pdf (accessed 10 May 2019).

Frontier Economics (2012), Enablers and Barriers to Integrated Care and Implications for Monitor, Frontier Economics, London, available at: https://assets.publishing.service.gov.uk/government/ uploads/system/uploads/attachment_data/file/287800/Enablers_and_barriers_to_integrated_ care_report_June_2012.pdf (accessed 10 May 2019).

Goodwin, N., Sonola, L., Thiel, V. and Kodner, D.L. (2013), Co-ordinated Care for People with Complex Conditions, Key lessons and Markers for Success, The King's Fund, London, available at: www. kingsfund.org.uk/sites/default/files/field/field_publication_file/co-ordinated-care-for-peoplewith-complex-chronic-conditions-kingsfund-oct13.pdf (accessed 10 May 2019).

Hughes, L.C. and Preski, S. (1997), "Using key informant methods in organizational research: assessing for informant bias", Research in Nursing \& Health, Vol. 20 No. 1, pp. 81-92. 
Knight, S. (2018), "Britain's austerity has officially ended - and yet it's still going”, The New Yorker, 3 November, available at: www.newyorker.com/news/letter-from-the-uk/britains-austerity-hasofficially-ended-yet-its-still-going (accessed 1 July 2019).

Mezias, J.M. and Starbuck, W.H. (2003), "Studying the accuracy of managers' perceptions: a research odyssey", British Journal of Management, Vol. 14 No. 1, pp. 3-17.

National Collaboration for Integrated Care and Support (2013), "Integrated care and support: our shared commitment", May, available at: https://assets.publishing.service.gov.uk/government/uploads/ system/uploads/attachment_data/file/198748/DEFINITIVE_FINAL_VERSION_Integrated_Care_ and_Support_-_Our_Shared_Commitment_2013-05-13.pdf (accessed 10 May 2019).

National Voices and Think Local Act Personal (2013, May), A Narrative for Person-Centred Coordinated Care, NHS, England, available at: www.england.nhs.uk/wp-content/uploads/2013/0 5/nv-narrative-cc.pdf (accessed 10 May 2019).

NHS England (2015), "Integrated Personal Commissioning (IPC) programme", available at: www. england.nhs.uk/commissioning/ipc (accessed 10 May 2019).

NHS England (2019), “The NHS Long Term Plan”, available at: www.longtermplan.nhs.uk/wp-content/ uploads/2019/01/nhs-long-term-plan.pdf (accessed 10 May 2019).

NHS England and Partners (2014), Five Year Forward View, NHS England, Public Health England, Monitor, Health Education England, the Care Quality Commission and the NHS Trust Development Authority, London, available at: www.england.nhs.uk/wp-content/uploads/2014/ 10/5yfv-web.pdf (accessed 10 May 2019).

Raleigh, V., Bardsley, M., Smith, P., Wistow, G., Wittenberg, R., Erens, B. and Mays, N. (2014), "Integrated care and support Pioneers: indicators for measuring the quality of integrated care", final report, Policy Innovation Research Unit, London, available at: http://piru.lshtm.ac.uk/ assets/files/IC_and_support_Pioneers-Indicators.pdf (accessed 10 May 2019).

RAND Europe, Ernst \& Young (2012), "National Evaluation of the Department of Health's Integrated Care Pilots: final report”, RAND Europe, Cambridge, available at: www.rand.org/content/dam/ rand/pubs/technical_reports/2012/RAND_TR1164.pdf (accessed 10 May 2019).

Von Korff, M., Wickizer, T., Maeser, J., O'Leary, P., Pearson, D. and Beery, W. (1992), "Community activation and health promotion: identification of key organizations", American Journal of Health Promotion, Vol. 7 No. 2, pp. 110-117.

Wilkes, L. (2014), Break on Through: Overcoming Barriers to Integration, New Local Government Network, London, available at: www.nlgn.org.uk/public/wp-content/uploads/BREAK-ONTHROUGH2.pdf (accessed 10 May 2019).

Windle, K., Wagland, R., Forder, J., D’Amico, F., Janssen, D. and Wistow, G. (2009), "National Evaluation of Partnerships for Older People Projects: final report", Personal Social Services Research Unit, available at: www.pssru.ac.uk/pub/dp2700.pdf (accessed 10 May 2019).

\section{Further reading}

Erens, B., Wistow, G., Durand, MA., Mounier-Jack, S., Manacorda, T., Douglas, N., Hoomans, T. and Mays, N. (2017a), Results from the First Survey (Spring 2016) of Pioneer Key Informants, Policy Innovation Research Unit, London, available at: http:/piru.lshtm.ac.uk/assets/files/First\%20key \%20informant\%20survey\%20report.pdf (accessed 10 May 2019).

\section{Corresponding author}

Bob Erens can be contacted at: bob.erens@1shtm.ac.uk

For instructions on how to order reprints of this article, please visit our website:

www.emeraldgrouppublishing.com/licensing/reprints.htm

Or contact us for further details: permissions@emeraldinsight.com 